\title{
Performance Analysis of Blind Multiuser Detectors for Cdma
}

\author{
S. Anuradha ${ }^{1}$, K. V. V. S. Reddy ${ }^{2}$ \\ ${ }^{1}$ ECE, National Institute of Technology, Warangal, 506004, India \\ ${ }^{2} \mathrm{ECE}$, Andhra University, Visakhapatnam, India
}

\begin{abstract}
This paper deals with the performance of blind multiuser detectors for CDMA is analyzed. The blind multiuser detectors are Direct Matrix Inversion (DMI) blind detector and subspace blind detector. The performance analysis is performed by means of the Signal to Interference Noise Ration (SINR) and Bit Error Rate (BER). The numerical results are plotted as variation of SINR Vs SNR and $\rho$, SINR with respect to correlation coefficient $(\rho)$ and BER Vs signal samples (M) using MAT LAB software. It is observed that the SINR Vs SNR and $\rho$ for both blind detectors. The performance of subspace blind detector deteriorates in the high cross correlation and low SNR region whereas the performance of the DMI blind detector is less sensitive to cross correlation and SNR in this region. The performance gain offered by the subspace detector is significant for smaller value of $\mathrm{K}$, and the gain diminishes as $\mathrm{K}$ increases. For large number of signal samples (M), both detectors converge to the true linear MMSE detector, with the subspace blind detector converging much faster than the DMI blind detector and the performance gain offered by the subspace detector is quite significant for small values of M. The BER performance of subspace approach is better than the DMI approach with increasing SNR.
\end{abstract}

Keywords CDMA, DMI, Subspace Blind Detector, MMSE

\section{Introduction}

Code Division Multiple Access (CDMA) implemented with direct-sequence spread-spectrum (DS-SS) modulation is emerging as a popular multiple-access technology for personal, cellular and satellite communication services[4]. Multiuser detection techniques can substantially increase the capacity of CDMA systems. Over the past decade, a significant amount of research has addressed various multiuser detection schemes. Considerable recent attention has been focused on adaptive multiuser detection[8]. For example, methods for adapting the decorrelating, or zero-forcing, linear detector that require the transmission of training sequences during adaptation have been proposed in[9], and[10]. An alternative linear detector, the minimum-mean-square-er ror (MMSE) detector, however, can be adapted either through the use of training sequences or in the blind mode, i.e., with the prior knowledge of only the signature waveform and timing of the user of interest adaptation schemes are especially attractive for the downlinks of CDMA systems, since in a dynamic environment, it is very difficult for a mobile user to obtain accurate information on other active users in the channel, such as their signature waveforms; and

* Corresponding author:

anu_praise2004@yahoo.co.in (S. Anuradha)

Published online at http://journal.sapub.org/jwnc

Copyright (C) 2012 Scientific \& Academic Publishing. All Rights Reserved the frequent use of training sequence is certainly a waste of channel bandwidth. There are primarily two approaches to blind multiuser detection, the direct matrix inversion (DMI) approach and the subspace approach. In this paper, we propose a new blind multiuser detection schemes which is based on DMI and signal subspace estimation. Subspace-based high-resolution methods play an important role in sensor array processing, spectrum analysis, and general parameter estimation[11].

The contribution of this work is based on signal subspace estimation, both the decorrelating detector and the linear MMSE detector can be obtained blindly, i.e., they can be estimated from the received signal with the prior knowledge of only the signature waveform and timing of the user of interest.

\section{Synchronous CDMA Model}

A baseband, K-user, time-invariant, synchronous additive white Gaussian noise (AWGN) system, employing periodic (short) spreading sequences, and operating with a coherent BPSK modulation format. The continues-time waveform received by a given user in such a system can be modeled as follows[1].

$\mathrm{r}(\mathrm{t})=\sum_{\mathrm{k}=1}^{\mathrm{K}} \mathrm{A}_{\mathrm{k}} \sum_{\mathrm{i}=0}^{\mathrm{M}-1} \mathrm{~b}_{\mathrm{k}}[\mathrm{i}] \mathrm{s}_{\mathrm{k}}(\mathrm{t}-\mathrm{iT})+\mathrm{n}(\mathrm{t}), 0 \leq \mathrm{t} \leq \mathrm{MT}$

where $\mathrm{M}$ is the number of data symbols per user in the data frame of interest; $T$ is the symbol interval; $A_{k}$, 
$\left\{b_{\mathrm{k}}[\mathrm{i}]\right\}_{\mathrm{i}=0}^{\mathrm{M}-1}$ and $\mathrm{s}_{\mathrm{k}}(\mathrm{t})$ denote respectively the received complex amplitude, the transmitted symbol stream and the normalized signaling waveform of the $\mathrm{k}^{\text {th }}$ user and $\mathrm{n}(\mathrm{t})$ is the baseband complex Gaussian ambient noise with independent real and imaginary components and with power spectral density $\sigma^{2}$. It is assumed that for each user $\mathrm{k}$, $\left\{b_{k}[i]\right\}_{i=0}^{\mathrm{M}-1}$ is a collection of independent equiprobable \pm 1 random variables, and the symbol streams of different users are independent. For direct-sequence spread-spectrum format, each user's signaling waveform is of the form

$$
\mathrm{s}_{\mathrm{k}}(\mathrm{t})=\frac{1}{\sqrt{\mathrm{N}}} \sum_{\mathrm{j}=0}^{\mathrm{N}-1} \mathrm{c}_{\mathrm{j}, \mathrm{k}} \psi\left(\mathrm{t}-\mathrm{j} \mathrm{T}_{\mathrm{c}}\right), 0 \leq \mathrm{t}<T
$$

where $\mathrm{N}$ is the processing gain; $\left\{\mathrm{c}_{\mathrm{j}, \mathrm{k}}\right\}_{\mathrm{j}=0}^{\mathrm{N}-1}$ is a signature sequence of \pm 1 's assigned to the kth user; and $\psi(\cdot)$ is a chip waveform of duration $\mathrm{T}_{\mathrm{c}}=\frac{\mathrm{T}}{\mathrm{N}}$ and with unit energy[i.e., $\left.\int_{0}^{T_{c}} \psi(t)^{2} d t=1\right]$

At the receiver, the received signal $r(t)$ is filtered by a chip-matched filter and then sampled at the chip rate. The sample corresponding to the $j^{\text {th }}$ chip of the $i^{\text {th }}$ symbol is given by

$$
\begin{gathered}
r_{j}[i] \triangleq \int_{i T+j T_{c}}^{i T+(j+1) T_{c}} r(t) \psi\left(t-i T-j T_{c}\right) d t, \\
j=0, \ldots, N-1 ; \quad i=0, \ldots, M-1
\end{gathered}
$$

The resulting discrete-time signal corresponding to the ith symbol is then given by

$$
\begin{aligned}
\mathbf{r}[\mathrm{i}] & =\sum_{\mathrm{k}=1}^{\mathrm{K}} \mathrm{A}_{\mathrm{k}} \mathrm{b}_{\mathrm{k}}[\mathrm{i}] \mathbf{s}_{\mathrm{k}}+\mathbf{n}[\mathrm{i}] \\
& =\mathbf{S A b}[\mathrm{i}]+\mathbf{n}[\mathrm{i}]
\end{aligned}
$$

With

$$
\mathbf{b}=\left[\begin{array}{c}
\mathrm{r}_{0}[\mathrm{i}] \\
\mathrm{r}_{1}[\mathrm{i}] \\
\vdots \\
\mathrm{r}_{\mathrm{N}-1}[\mathrm{i}]
\end{array}\right], \quad \mathbf{s}_{\mathrm{k}}=\frac{1}{\sqrt{\mathrm{N}}}\left[\begin{array}{c}
\mathrm{c}_{0, \mathrm{k}} \\
\mathrm{c}_{1, \mathrm{k}} \\
\vdots \\
\mathrm{c}_{\mathrm{N}-1, \mathrm{k}}
\end{array}\right], \mathbf{n}[\mathrm{i}] \triangleq\left[\begin{array}{c}
\mathrm{n}_{0}[\mathrm{i}] \\
\mathrm{n}_{1}[\mathrm{i}] \\
\vdots \\
\mathrm{n}_{\mathrm{N}-1}[\mathrm{i}]
\end{array}\right]
$$

where $n_{j}[i] \triangleq \int_{i T+j T_{c}}^{i T+(j+1) T_{c}} n(t) \psi\left(t-i T-j T_{c}\right) d t$ is a complex Gaussian random variable with independent real and imaginary components; $\mathbf{n}[\mathrm{i}] \sim \mathcal{N}_{\mathrm{c}}\left(0, \sigma^{2} \mathbf{I}_{\mathrm{N}}\right)$ (Here $\mathcal{N}_{\mathrm{c}}(\cdot, \cdot)$ denotes a complex Gaussian distribution, and $\mathbf{I}_{\mathrm{N}}$ denotes the $\mathrm{N} \times \mathrm{N}$ identity matrix. $) ; \mathbf{S}=\left[\mathbf{s}_{1} \cdots \mathbf{s}_{\mathrm{K}}\right] ; \mathbf{A}=\operatorname{diag}\left(\mathrm{A}_{1}, \cdots\right.$ , $\left.A_{K}\right)$; and $\mathbf{b}[\mathrm{i}]=\left[b_{1}[\mathrm{i}] \cdots \mathrm{b}_{\mathrm{K}}[\mathrm{i}]\right]^{\mathrm{T}}$.

Suppose that we are interested in demodulating the data bits of a particular user, say user $1,\left\{b_{\mathrm{k}}[\mathrm{i}]\right\}_{\mathrm{i}=0}^{\mathrm{M}-1}$, based on the received waveforms $\{\mathrm{r}[\mathrm{i}]\}_{\mathrm{i}=0}^{\mathrm{M}-1}$. A linear receiver for this purpose is described by a weight vectorw $\mathbf{w}_{1} \in \mathbb{C}^{\mathrm{N}}$, such that the desired user's data bits are demodulated according to

$$
\begin{aligned}
& \mathrm{z}_{1}[\mathrm{i}]=\mathrm{w}_{1}^{\mathrm{H}} \mathrm{r}[\mathrm{i}] \\
& \hat{\mathrm{b}}_{1}[\mathrm{i}]=\operatorname{sign}\left\{\Re\left(\mathrm{A}_{1}^{*} \mathrm{z}_{1}[\mathrm{i}]\right)\right\}
\end{aligned}
$$

In case that the complex amplitude $A_{1}$ of the desired user is unknown, we can resort to differential detection. Define the differential bit as

$$
\beta_{1}[\mathrm{i}] \triangleq \mathrm{b}_{1}[\mathrm{i}] \mathrm{b}_{1}[\mathrm{i}-1] .
$$

Then using the linear detector output, the following differential detection rule can be used

$$
\widehat{\beta}_{1}=\operatorname{sign}\left\{\Re\left(\mathrm{z}_{1}[\mathrm{i}] \mathrm{z}_{1}[\mathrm{i}-1]^{*}\right)\right\}
$$

Substituting $\mathbf{r}[\mathrm{i}] \mathrm{inz}_{1}[\mathrm{i}]$, the output of the linear receiver $\mathbf{w}_{1}$ can be written as

$$
\mathrm{z}_{1}[\mathrm{i}]=\mathrm{A}_{1}\left(\mathbf{w}_{1}^{\mathrm{H}} \mathbf{s}_{1}\right) \mathrm{b}_{1}[\mathrm{i}]+\sum_{\mathrm{k}=2}^{\mathrm{K}} \mathrm{A}_{\mathrm{k}}\left(\mathbf{w}_{1}^{\mathrm{H}} \mathbf{s}_{\mathrm{k}}\right) \mathrm{b}_{\mathrm{k}}[\mathrm{i}]+\mathbf{w}_{1}^{\mathrm{H}} \mathbf{n}[\mathrm{i}]
$$

The first term contains the useful signal of the desired user; the second term contains the signals from other undesired users - the so-called multiple-access interference(MAI); and the last term contains the ambient Gaussian noise. The simplest linear receiver is the conventional matched-filter, wherew $_{1}=s_{1}$. A matched filter receiver is optimal only in a single-user channel (i.e., $\mathrm{K}=1$ ). In a multiuser channel (i.e., $\mathrm{K}>1$ ), this receiver may perform poorly since it makes no attempt to ameliorate the MAI, a limiting source of interference in multiple-access channels. Two popular forms of linear detectors that are capable of suppressing the MAI are the linear decorrelating detector and the linear minimum mean-square error (MMSE) detector, which are discussed next.

\section{Linear Multi User Detectors.}

\section{a. Direct Matrix Inversion (DMI) approach}

For the linear MMSE detector, directly solving the optimization problem we obtain

$$
\begin{aligned}
\mathrm{m}_{1}=\arg \min _{\mathbf{w} \in \mathbb{C}^{\mathrm{N}}}[\mathbf{w}^{\mathrm{H}} \underbrace{\mathrm{E}\left\{\mathbf{r}[\mathrm{i}] \mathbf{r}[\mathrm{i}]^{\mathrm{H}}\right\}}_{\mathbf{C}_{\mathrm{r}}} \mathbf{w} \\
\left.\quad-2 \mathbf{w}^{\mathrm{H}}\{\mathrm{A}_{1}^{*} \underbrace{\mathrm{E}\left(\mathbf{r}[\mathrm{i}] \mathrm{b}_{1}[\mathrm{i}]\right)}_{\mathrm{A}_{1} \mathbf{s}_{1}}\}\right] \\
=\left|\mathrm{A}_{1}\right|^{2} \mathbf{C}_{\mathrm{r}}^{-1} \mathrm{~s}_{1} .
\end{aligned}
$$

Where

$$
\mathbf{C}_{\mathrm{r}} \triangleq \mathrm{E}\left\{\mathbf{r}[\mathrm{i}] \mathbf{r}[\mathrm{i}]^{\mathrm{H}}\right\}=\mathbf{S}|\mathbf{A}|^{2} \mathbf{S}^{\mathrm{H}}+\sigma^{2} \mathbf{I}_{\mathrm{N}},
$$

is the autocorrelation matrix of the received signal. Note that $\mathbf{C}_{\mathrm{r}}$ can be estimated from the received signals by the corresponding sample autocorrelation. Note also that the constant $|\mathbf{A}|^{2}$ does not affect the linear decision rule. Hence MMSE detector leads straight forwardly to the following blind implementation of the linear MMSE detector the so-called direct matrix inversion (DMI) blind detector. Here we do not assume knowledge of the complex amplitude of the desired user; hence differential detection will be employed.

\subsection{DMI Blind Linear MMSE Detector - Synchronous CDMA}

1. Compute the detector:

$$
\begin{aligned}
\widehat{\mathbf{C}}_{\mathrm{r}}=\frac{1}{\mathrm{M}} \sum_{\mathrm{i}=0}^{\mathrm{M}-1} \mathbf{r}[\mathrm{i}] \mathbf{r}[\mathrm{i}]^{\mathrm{H}}, \\
\widehat{\mathbf{m}}_{1}=\widehat{\mathbf{C}}_{\mathrm{r}}^{-1} \mathbf{s}_{1}
\end{aligned}
$$

2. Perform differential detection:

$$
\mathrm{z}_{1}[\mathrm{i}]=\widehat{\mathbf{m}}_{1}^{\mathrm{H}} \mathbf{r}[\mathrm{i}],
$$

$$
\widehat{\beta}_{1}[\mathrm{i}]=\operatorname{sign}\left\{\Re\left(\mathrm{z}_{1}[\mathrm{i}] \mathrm{z}_{1}[\mathrm{i}-1]^{*}\right)\right\}, \quad=1, \ldots \mathrm{M}-1
$$

The above algorithm is a batch processing method, i.e., it computes the detector only once based on a block of received signals $\{\mathbf{r}[\mathrm{i}]\}_{\mathrm{i}=0}^{\mathrm{M}-1}$; and the estimated detector is then used to detect all data bits of the desired user contained in the same 
signal block, $\left\{b_{1}[i]\right\}_{i=0}^{M-1}$. The idea is to perform sequential detector estimation and data detection. That is, suppose that at time $(i-1)$, an estimated detector $\mathbf{m}_{1}[i-1]$ is employed to detect the data bit $b_{1}[i-1]$. At time $i$, a new signalr $[\mathrm{i}]$ is received which is then used to update the detector estimate to obtain $\mathbf{m}_{1}[\mathrm{i}]$. The updated detector is used to detect the data bit $b_{1}[i]$. Hence the blind detector is sequentially updated at the symbol rate. In order to develop such an adaptive algorithm, we need an alternative characterization of the linear MMSE detector[7].

\section{b. Subspace approach}

This approach is based on estimating the signal subspace spanned by the user signature waveforms. This approach leads to blind implementation of both the linear decorrelating detector and the linear MMSE detector. It also offers a number of advantages over the direct methods[2].

Assume that the spreading waveforms $\left\{\mathbf{s}_{\mathrm{k}}\right\}_{\mathrm{k}=1}^{\mathrm{K}}$ of $\mathrm{K}$ users are linearly independent. Note that $\mathbf{C}_{\mathrm{r}}$ is the sum of the rank-K matrix $\mathbf{S}|\mathbf{A}|^{2} \mathbf{S}^{\mathrm{H}}$ and the identity matrix $\sigma^{2} \mathbf{I}_{\mathrm{N}}$.This matrix then has $\mathrm{K}$ Eigen values that are strictly larger than $\sigma^{2}$, and $(\mathrm{N}-\mathrm{K})$ Eigen values that equal to $\sigma^{2}$.Its Eigen decomposition can be written as

$$
\mathbf{C}_{\mathrm{r}}=\mathbf{U}_{\mathrm{s}} \boldsymbol{\Lambda}_{\mathrm{s}} \mathbf{U}_{\mathrm{s}}^{\mathrm{H}}+\sigma^{2} \mathbf{U}_{\mathrm{n}} \mathbf{U}_{\mathrm{n}}^{\mathrm{H}}
$$

Where $\boldsymbol{\Lambda}_{\mathrm{s}}=\operatorname{diag}\left(\lambda_{1}, \cdots, \lambda_{\mathrm{K}}\right)$ contains the largest $\mathrm{K}$ Eigen values of $\mathbf{C}_{\mathrm{r}}, \mathbf{U}_{\mathrm{s}}=\left[\mathbf{u}_{1}, \cdots, \mathbf{u}_{\mathrm{K}}\right]$ contains the $\mathrm{K}$ orthogonal eigenvectors corresponding to the largest $\mathrm{K}$ Eigen values in $\boldsymbol{\Lambda}_{\mathrm{s}} ; \mathbf{U}_{\mathrm{n}}=\left[\mathbf{u}_{\mathrm{K}+1}, \cdots, \mathbf{u}_{\mathrm{N}}\right]$ contains the $(\mathrm{N}-\mathrm{K})$ orthogonal Eigen vectors corresponding to the smallest Eigen value $\sigma^{2}$ of $\mathbf{C}_{\mathrm{r}}$. It is easy to see thatrange $(\mathbf{S})=\operatorname{range}\left(\mathbf{U}_{\mathrm{s}}\right)$. The column space of $\mathbf{U}_{S}$ is called the signal subspace and its orthogonal complement, the noise subspace, is spanned by the columns of. $\mathbf{U}_{\mathrm{n}}$

\section{Linear Decorrelating Detector}

The linear decorrelating detector is characterized by the following results.

1. The linear decor relating detector $\mathbf{d}_{1}$ is the unique weight vector $\mathbf{w} \in$ range $\left(\mathbf{U}_{\mathrm{s}}\right)$, such that $\mathbf{w}^{\mathrm{H}} \mathbf{s}_{1}=1$, and $\mathbf{w}^{\mathrm{H}} \mathbf{s}_{\mathrm{k}}=0$, fork $=2, \cdots, \mathrm{K}$.

Proof: Since rank $\left(\mathbf{U}_{\mathrm{s}}\right)=\mathrm{K}$, the vector $\mathbf{w}$ that satisfies the above conditions exists and is unique.

2. The decor relating detector $\mathbf{d}_{1}$ is the unique weight vector $\mathbf{w} \in$ range $\left(\mathbf{U}_{\mathrm{s}}\right)$ that minimizes $\phi(\mathbf{w})=$ $\mathrm{E}\left\{\left\|\mathbf{w}^{\mathrm{H}}(\mathbf{S A b})\right\|^{2}\right\}$, subject to $\mathbf{w}^{\mathrm{H}} \mathbf{s}_{\mathbf{1}}=1$.

Proof: Since

$$
\begin{aligned}
\phi(\mathbf{w}) & =\mathbf{w}^{\mathrm{H}} \mathrm{E}\left\{(\mathbf{S A b})(\mathbf{S A b})^{\mathrm{H}}\right\} \mathbf{w} \\
& =\mathbf{w}^{\mathrm{H}}\left(\mathbf{S}|\mathbf{A}|^{2} \mathbf{S}^{\mathrm{H}}\right) \mathbf{w} \\
& =\left|\mathrm{A}_{1}\right|^{2}\left|\mathbf{w}^{\mathrm{H}} \mathbf{s}_{1}\right|^{2}+\sum_{\mathrm{k}=2}^{\mathrm{K}}\left|\mathrm{A}_{\mathrm{k}}\right|^{2}\left|\mathbf{w}^{\mathrm{H}} \mathbf{s}_{\mathrm{k}}\right|^{2} \\
& =\left|\mathrm{A}_{1}\right|^{2}+\sum_{\mathrm{k}=2}^{\mathrm{K}}\left|\mathrm{A}_{\mathrm{k}}\right|^{2}\left|\mathbf{w}^{\mathrm{H}} \mathbf{s}_{\mathrm{k}}\right|^{2},
\end{aligned}
$$

it then follows that for $\mathbf{w} \in \operatorname{range}\left(\mathbf{U}_{\mathrm{s}}\right)=\operatorname{range}\left(\mathbf{U}_{\mathrm{s}}\right)$, $\phi(\mathbf{w})$ is minimized if and only if $\mathbf{w}^{\mathrm{H}} \mathbf{s}_{\mathrm{k}}=0$, for $\mathrm{k}=2, \ldots, \mathrm{K}$. The unique solution is $\mathbf{w}=\mathbf{d}_{1}$.

The linear decorrelating detector $\mathbf{d}_{1}$ is given in terms of the signal subspace parameters by

$$
\begin{array}{ll}
\mathbf{d}_{1}= & \alpha_{\mathrm{d}} \mathbf{U}_{\mathrm{s}}\left(\boldsymbol{\Lambda}_{\mathrm{s}}-\sigma^{2} \mathbf{I}_{\mathrm{K}}\right)^{-1} \mathbf{U}_{\mathrm{s}}^{\mathrm{H}} \mathbf{s}_{1} \\
\text { with } \quad & \alpha_{\mathrm{d}} \triangleq\left[\mathbf{s}_{1}^{\mathrm{H}} \mathbf{U}_{\mathrm{s}}\left(\boldsymbol{\Lambda}_{\mathrm{s}}-\sigma^{2} \mathbf{I}_{\mathrm{K}}\right)^{-1} \mathbf{U}_{\mathrm{s}}^{\mathrm{H}} \mathbf{s}_{1}\right]^{-1}
\end{array}
$$

Proof: A vector $\mathbf{w} \in$ range $\left(\mathbf{U}_{\mathrm{s}}\right)$ if and only if it can be written as, $\mathbf{w}=\mathbf{U}_{\mathrm{s}} \mathbf{x}$ for some. $\mathbf{x} \in \mathbb{C}^{\mathrm{K}}$ The linear decorrelating detector $\mathbf{d}_{1}$ has the form $\mathbf{d}_{1}=\mathbf{U}_{\mathrm{s}} \mathbf{x}_{1}$, where

$$
\begin{gathered}
\mathbf{x}_{1}=\arg \min _{\mathbf{x} \in \mathbb{C}_{\mathrm{K}}}\left(\mathbf{U}_{\mathrm{S}} \mathbf{x}\right)^{\mathrm{H}}\left(\mathbf{S}|\mathbf{A}|^{2} \mathbf{S}^{\mathrm{H}}\right)\left(\mathbf{U}_{\mathrm{s}} \mathbf{x}\right) \text {, s.t. }\left(\mathbf{U}_{\mathrm{s}} \mathbf{x}\right)^{\mathrm{H}} \mathbf{s}_{1}=1, \\
=\arg \min _{\mathbf{x} \in \mathbb{C}_{\mathrm{K}}} \mathbf{x}^{\mathrm{H}}\left[\mathbf{U}_{\mathrm{s}}^{\mathrm{H}}\left(\mathbf{S}|\mathbf{A}|^{2} \mathbf{S}^{\mathrm{H}}\right) \mathbf{U}_{\mathrm{s}}\right] \mathbf{x}, \text { s.t. } \mathbf{x}^{\mathrm{H}}\left(\mathbf{U}_{\mathrm{s}}^{\mathrm{H}} \mathbf{s}_{1}\right)=1, \\
=\arg \min _{\mathbf{x} \in \mathbb{C}_{\mathrm{K}}} \mathbf{x}^{\mathrm{H}}\left(\boldsymbol{\Lambda}_{\mathrm{s}}-\sigma^{2} \mathbf{I}_{\mathrm{K}}\right) \mathbf{x} \text {, s.t. } \mathbf{x}^{\mathrm{H}}\left(\mathbf{U}_{\mathrm{s}}^{\mathrm{H}} \mathbf{s}_{1}\right)=1
\end{gathered}
$$

Where the third equality follows from the fact that

$$
\mathbf{S}|\mathbf{A}|^{2} \mathbf{S}^{\mathrm{H}}=\mathbf{U}_{\mathrm{s}}\left(\boldsymbol{\Lambda}_{\mathrm{s}}-\sigma^{2} \mathbf{I}_{\mathrm{K}}\right) \mathbf{U}_{\mathrm{s}}^{\mathrm{H}}
$$

From the method of Lagrange multipliers

$$
\left(\Lambda_{\mathrm{s}}-\sigma_{2} \mathrm{I}_{\mathrm{K}}\right) \mathrm{x}_{1}=\alpha_{\mathrm{d}} \mathrm{U}_{\mathrm{s}}^{\mathrm{H}} \mathrm{s}_{1}
$$

Therefore $\mathrm{x}_{1}=\alpha_{\mathrm{d}}\left(\Lambda_{\mathrm{s}}-\sigma^{2} \mathrm{I}_{\mathrm{K}}\right)^{-1} \mathrm{U}_{\mathrm{s}}^{\mathrm{H}} \mathrm{s}_{1}$, where $\alpha_{\mathrm{d}}$ is determined from the constraint $\left(\mathrm{U}_{\mathrm{s}} \mathrm{x}_{1}\right)^{\mathrm{H}} \mathrm{s}_{1}=1$, that is $\alpha_{\mathrm{d}}=$ $\left(s_{1}^{\mathrm{H}} U_{s}\left(\Lambda_{s}-\sigma^{2} I_{K}\right)^{-1} U_{s}^{H} s_{1}\right)^{-1}$. Finally weight vector of the linear decorrelating detector is given by $\mathrm{d}_{1}=\mathrm{U}_{\mathrm{s}} \mathrm{x}_{1}=$ $\alpha_{d} U_{s}\left(\Lambda_{s}-\sigma^{2} I_{K}\right)^{-1} U_{s}^{H} s_{1}$.

\section{Linear MMSE detector:}

The following result gives the subspace form of the linear MMSE detector.

The weight vector $m_{1}$ of the linear MMSE detector is given in terms of the signal subspace parameters by

With

$$
\mathbf{m}_{1}=\alpha_{\mathrm{m}} \mathbf{U}_{\mathrm{s}} \boldsymbol{\Lambda}_{\mathrm{s}}^{-1} \mathbf{U}_{\mathrm{s}}^{\mathrm{H}} \mathbf{s}_{1}
$$

$$
\alpha_{\mathrm{m}}=\left(\mathbf{s}_{1}^{\mathrm{H}} \mathbf{U}_{\mathrm{s}} \boldsymbol{\Lambda}_{\mathrm{s}}^{-1} \mathbf{U}_{\mathrm{s}}^{\mathrm{H}} \mathbf{s}_{1}\right)^{-1}
$$

Proof: The linear MMSE detector defined by

$$
\begin{aligned}
& \mathbf{m}_{1}=\mathbf{C}_{\mathrm{r}}^{-1} \mathbf{s}_{1}\left(\mathbf{s}_{1}^{\mathrm{H}} \mathbf{C}_{\mathrm{r}}^{-1} \mathbf{s}_{1}\right)^{-1} \\
& \mathbf{C}_{\mathrm{r}}^{-1}=\mathbf{U}_{\mathrm{s}} \boldsymbol{\Lambda}_{\mathrm{s}}^{-1} \mathbf{U}_{\mathrm{s}}^{\mathrm{H}}+\frac{1}{\sigma^{2}} \mathbf{U}_{\mathrm{n}} \mathbf{U}_{\mathrm{n}}^{\mathrm{H}}
\end{aligned}
$$

Substituting $\mathbf{C}_{\mathrm{r}}^{-1}$ into $\mathbf{m}_{1}$ and using the fact that $\mathbf{U}_{\mathrm{n}}^{\mathrm{H}} \mathbf{s}_{1}=$ 0, obtain the result.

\section{Subspace blind linear detectors - synchronous CDMA}

1. Compute the detector:

$$
\begin{aligned}
& \widehat{\mathbf{C}}_{\mathrm{r}}=\frac{1}{\mathrm{M}} \sum_{\mathrm{i}=0}^{\mathrm{M}-1} \mathbf{r}[\mathrm{i}] \mathbf{r}[\mathrm{i}]^{\mathrm{H}}, \\
& \quad=\widehat{\mathbf{U}}_{\mathrm{s}} \widehat{\boldsymbol{\Lambda}}_{\mathrm{s}} \widehat{\mathbf{U}}_{\mathrm{s}}^{\mathrm{H}}+\widehat{\mathbf{U}}_{\mathrm{n}} \widehat{\boldsymbol{\Lambda}}_{\mathrm{n}} \widehat{\mathbf{U}}_{\mathrm{n}}^{\mathrm{H}}
\end{aligned}
$$

$\hat{\mathbf{d}}_{1}=\widehat{\mathbf{U}}_{\mathrm{s}}\left(\widehat{\boldsymbol{\Lambda}}_{\mathrm{s}}-\sigma^{2} \mathbf{I}_{\mathrm{K}}\right) \widehat{\mathbf{U}}_{\mathrm{s}}^{\mathrm{H}} \mathbf{s}_{1}$, (linear decorrelating detector)

$$
\widehat{\mathbf{m}}_{1}=\widehat{\mathbf{U}}_{\mathrm{s}} \widehat{\boldsymbol{\Lambda}}_{\mathrm{s}} \widehat{\mathbf{U}}_{\mathrm{s}}^{\mathrm{H}} \mathbf{s}_{1} \text {, (linear MMSE detector) }
$$

\section{Performance Measures}

In the paper discussed two approaches to blind multiuser detection - namely, the direct method and the subspace method. These two approaches are based primarily on two equivalent expressions for the linear MMSE detector. When the autocorrelation $\mathrm{C}_{\mathrm{r}}$ of the received signals is known exactly, the two approaches have the same performance[3],[5],[6]. However, when $\mathbf{C}_{r}$ is replaced by the corresponding sample autocorrelation quite interestingly, the performance of these two methods is very different. This is due to the fact that these two approaches exhibit different estimation errors on the estimated detector. In this section, we present performance analysis of the two blind multiuser detectors - the DMI blind detector and the subspace blind detector. For simplicity[6], we consider only real-valued 
signals, i.e $\mathrm{A}_{\mathrm{k}}>0, k=1, \cdots, K$ and. $\mathbf{n}[\mathrm{i}] \sim \mathrm{N}\left(0, \sigma^{2} \mathbf{I}_{\mathrm{N}}\right)$

Suppose a linear weight vector $\mathbf{w}_{1} \in \mathbb{R}^{\mathrm{N}}$ is applied to the received signal $\mathbf{r}[\mathrm{i}]$ in (5). Since it is assumed that the user bit streams are independent, and the noise is independent of the user bits, the signal-to-interference-plus-noise ratio (SINR) at the output of the linear detector is given by

$$
\begin{aligned}
\operatorname{SINR}\left(\mathbf{w}_{1}\right) & =\frac{\mathrm{E}\left\{\mathbf{w}_{1}^{\mathrm{T}} \mathbf{r}[\mathrm{i}] \mid \mathrm{b}_{1}[\mathrm{i}]\right\}^{2}}{\mathrm{E}\left\{\operatorname{Var}\left\{\mathbf{w}_{1}^{\mathrm{T}} \mathbf{r}[\mathrm{i}] \mid \mathrm{b}_{1}[\mathrm{i}]\right\}\right.} \\
& =\frac{\mathrm{A}_{1}^{2}\left(\mathbf{w}_{1}^{\mathrm{T}} \mathbf{s}_{1}\right)^{2}}{\sum_{\mathrm{k}=2}^{\mathrm{K}} \mathrm{A}_{\mathrm{k}}^{2}\left(\mathbf{w}_{1}^{\mathrm{T}} \mathbf{s}_{\mathrm{k}}\right)^{2}+\sigma^{2}\left\|\mathbf{w}_{1}\right\|^{2}}
\end{aligned}
$$

The bit error probability of the linear detector using weight vector $\mathrm{w}_{1}$ is given by,

$$
\begin{aligned}
& \mathrm{P}_{\mathrm{e}}\left(\mathbf{w}_{1}\right)=\mathrm{P}\left(\hat{\mathrm{b}}_{1}[\mathrm{i}] \neq \mathrm{b}_{1}[\mathrm{i}]\right) \\
& \quad=\frac{1}{2^{\mathrm{K}-1}} \sum_{\left[\mathrm{b}_{2} \ldots \mathrm{b}_{\mathrm{k}}\right] \in\{-1,+1\}^{\mathrm{K}-1}} \mathrm{Q}\left(\mathrm{A}_{1} \mathbf{w}_{1}^{\mathrm{T}} \mathbf{s}_{1}+\frac{\sum_{\mathrm{k}=2}^{\mathrm{K}} \mathrm{A}_{\mathrm{k}} \mathrm{b}_{\mathrm{k}} \mathbf{w}_{1}^{\mathrm{T}} \boldsymbol{s}_{\mathrm{k}}}{\left\|\mathbf{w}_{1}\right\| \sigma^{2}}\right)
\end{aligned}
$$

Now suppose that an estimate $\widehat{\mathbf{w}}_{1}$ of the weight vector $\mathbf{w}_{1}$ is obtained from the received signals $\{\mathbf{r}[\mathrm{i}]\}_{\mathrm{i}=0}^{\mathrm{M}-1}$. Denote $\Delta \mathbf{w}_{1} \triangleq \widehat{\mathbf{w}}_{1}-\mathbf{w}_{1}$. Obviously both $\widehat{\mathbf{w}}_{1}$ and $\Delta \mathbf{w}_{1}$ are random vectors and are functions of the random quantities $\{\mathbf{b}[\mathrm{i}], \mathbf{n}[\mathrm{i}]\}_{\mathrm{i}=0}^{\mathrm{M}-1}$. In typical adaptive multiuser detection scenarios, the estimated detector $\widehat{\mathbf{w}}_{1}$ is employed to demodulate future received signals, say $\mathbf{r}[\mathrm{j}], \mathrm{j}>M$. Then the output is given by

$$
\widehat{\mathbf{w}}_{1}^{\mathrm{T}} \mathbf{r}[\mathrm{j}]=\mathbf{w}_{1}^{\mathrm{T}} \mathbf{r}[\mathrm{j}]+\Delta \mathbf{w}_{1}^{\mathrm{T}} \mathbf{r}[\mathrm{j}], \mathrm{j}>M,
$$

Where the first term represents the output of the true weight vector $\mathbf{w}_{1}$. The second term represents an additional noise term caused by the estimation error $\Delta \mathbf{w}_{1}$. Hence from the above equation, the average SINR at the output of any unbiased estimated linear detector $\widehat{\mathbf{w}}_{1}$ is given by

$$
\begin{aligned}
& \overline{\operatorname{SINR}\left(\widehat{\mathbf{w}}_{1}\right)}=\frac{\mathrm{A}_{1}^{2}\left(\mathbf{w}_{1}^{\mathrm{T}} \mathbf{s}_{1}\right)^{2}}{\sum_{\mathrm{k}=2}^{\mathrm{K}} \mathrm{A}_{\mathbf{k}}^{2}\left(\mathbf{w}_{1}^{\mathrm{T}} \mathbf{s}_{1}\right)^{2}+\sigma^{2}\left\|\mathbf{w}_{1}\right\|^{2}+\mathrm{E}\left\{\left(\Delta \mathbf{w}_{1}^{\mathrm{T}} \mathbf{r}[\mathrm{j}]\right)^{2}\right\}} \\
& \begin{aligned}
\mathrm{E}\left\{\left(\Delta \mathbf{w}_{1}^{\mathrm{T}} \mathbf{r}[\mathrm{j}]\right)^{2}\right\} & \left.=\operatorname{tr}\left(\mathrm{E}\left\{\Delta \mathbf{w}_{1}^{\mathrm{T}} \mathbf{r}[\mathrm{j}] \mathbf{r}[\mathrm{j}]\right]^{\mathrm{T}} \Delta \mathbf{w}_{1}\right\}\right) \\
= & \operatorname{tr}\left(\mathrm{E}\left\{\Delta \mathbf{w}_{1} \Delta \mathbf{w}_{1}^{\mathrm{T}} \mathbf{r}[\mathrm{j}] \mathbf{r}[\mathrm{j}]^{\mathrm{T}}\right\}\right) \\
= & \operatorname{tr}(\underbrace{\mathrm{E}\left\{\Delta \mathbf{w}_{1} \Delta \mathbf{w}_{1}^{\mathrm{T}}\right\}}_{\mathbf{C}_{\mathrm{w}}} \underbrace{\mathrm{E}\left\{\mathbf{r}[\mathrm{j}] \mathbf{r}[\mathrm{T}]^{\mathrm{T}}\right\}}_{\mathbf{C}_{\mathrm{r}}=\mathbf{S A}^{2} \mathbf{s}^{\mathrm{T}}+\sigma^{2} \mathbf{I}_{\mathrm{N}}}) \\
= & \frac{1}{\mathrm{M}} \operatorname{tr}\left(\mathbf{C}_{\mathrm{w}} \mathbf{C}_{\mathrm{r}}\right)
\end{aligned}
\end{aligned}
$$

Where $\mathbf{C}_{\mathrm{w}} \triangleq \mathrm{M} \cdot \mathrm{E}\left\{\Delta \mathbf{w}_{1} \Delta \mathbf{w}_{1}^{\mathrm{T}}\right\}$ and $\mathbf{C}_{\mathrm{r}} \triangleq \mathrm{E}\left\{\mathbf{r}[\mathrm{j}] \mathbf{r}[\mathrm{j}]^{\mathrm{T}}\right\}$. Since $\Delta \mathbf{w}_{1}$ is a function of $\{\mathbf{r}[\mathrm{i}]\}_{\mathrm{i}=0}^{\mathrm{M}-1}$, for a fixed i, $\Delta \mathbf{w}_{1}$ and $\mathbf{r}[\mathrm{i}]$ are in general correlated. For largeM, such correlation is small. Therefore in this case we still the above equations as the approximate SINR expression

\section{Asymptotic Output SINR}

We present the asymptotic distribution of the two forms of blind linear MMSE detectors, for large number of signal samples, M. Recall that in the direct-matrix-inversion (DMI) method, the blind multiuser detector is estimated according to

$$
\widehat{\mathbf{C}}_{\mathrm{r}}=\frac{1}{\mathrm{M}} \sum_{\mathrm{i}=1}^{\mathrm{M}} \mathbf{r}[\mathrm{i}] \mathbf{r}[\mathrm{i}]^{\mathrm{T}}
$$

$\widehat{\mathbf{w}}_{1}=\widehat{\mathbf{C}}_{\mathrm{r}}^{-1} \mathbf{s}_{1} \quad$ [DMIblindlinearMMSEdetector]

In the subspace method, the estimate of the blind detector is given by

$$
\begin{aligned}
\widehat{\mathbf{C}}_{\mathrm{r}}= & \frac{1}{\mathrm{M}} \sum_{\mathrm{i}=1}^{\mathrm{M}} \mathbf{r}[\mathrm{i}] \mathrm{r}[\mathrm{i}]^{\mathrm{T}} \\
& =\widehat{\mathbf{U}}_{\mathrm{s}} \widehat{\boldsymbol{\Lambda}}_{\mathrm{s}} \widehat{\mathbf{U}}_{\mathrm{s}}^{\mathrm{T}}+\widehat{\mathbf{U}}_{\mathrm{n}} \widehat{\boldsymbol{\Lambda}}_{\mathrm{n}} \widehat{\mathbf{U}}_{\mathrm{n}}^{\mathrm{T}}
\end{aligned}
$$

$\mathbf{w}_{1}=\mathbf{U}_{\mathrm{s}} \widehat{\boldsymbol{\Lambda}}_{\mathrm{s}} \widehat{\mathbf{U}}_{\mathrm{s}}^{\mathrm{T}} \mathbf{s}_{1} \quad$ [subspaceblindlinearMMSEdetector]

Where $\widehat{\boldsymbol{\Lambda}}_{\mathrm{s}}$ and $\widehat{\mathbf{U}}_{\mathrm{s}}$ contain respectively the largest $\mathrm{K}$ Eigen values and the corresponding Eigen vectors of; $\hat{\mathbf{C}}_{\mathrm{r}}$ and where $\widehat{\boldsymbol{\Lambda}}_{\mathrm{n}}$ and $\widehat{\mathbf{U}}_{\mathrm{n}}$ contain respectively the remaining Eigen values and eigenvectors of $\widehat{\mathbf{C}}_{\mathrm{r}}$.

The average output SINR of the estimated blind linear detector is given by,

$$
\begin{aligned}
& \overline{\operatorname{SINR}\left(\widehat{\boldsymbol{w}}_{1}\right)}= \\
& \overline{\sum_{k=2}^{K} A_{k}^{2}\left(w_{k}^{T} s_{k}\right)^{2}+\sigma^{2}\left\|\mid w_{1}\right\|^{2}+\frac{1}{M}\left[(K+1) w_{1}^{T} s_{1}-2 \sum_{k=2}^{K} A_{k}^{4}\left(w_{1}^{T} s_{k}\right)^{2}\left(w_{k}^{T} s_{k}\right)+(N-K) \tau \sigma^{2}\right]}
\end{aligned}
$$

Where

$$
\begin{aligned}
& \mathbf{w}_{1}^{\mathrm{T}} \mathbf{s}_{\mathrm{k}}=\frac{1}{\mathrm{~A}_{1}^{2}}\left[\mathbf{R}\left(\mathbf{R}+\sigma^{2} \mathbf{A}^{-2}\right)^{-1}\right]_{\mathrm{k}, \mathrm{l}}, \quad \mathrm{k}, \mathrm{l}=1, \ldots, \mathrm{K}, \\
&\left\|\mathbf{w}_{1}\right\|^{2}=\frac{1}{\mathrm{~A}_{1}^{4}}\left[\left(\mathbf{R}+\sigma^{2} \mathbf{A}^{-2}\right)^{-1} \mathbf{R}\left(\mathbf{R}+\sigma^{2} \mathbf{A}^{-2}\right)^{-1}\right]_{1,1}
\end{aligned}
$$

$\tau \sigma^{2}=$

$$
\left\{\begin{array}{l}
\mathbf{w}_{1}^{\mathrm{T}} \mathbf{s}_{1} \quad \text { (DMI blind detector) } \\
\frac{\sigma^{2}}{A_{1}^{4}}\left[\left(\mathbf{R}+\sigma^{2} \mathbf{A}^{-2}\right)^{-1} \mathbf{A}^{-2} \mathbf{R}^{-1}\right]_{1,1}(\text { subspace blind detector) }
\end{array}\right.
$$

It is seen here that the performance difference between the DMI blind detector and the subspace blind detector is caused by the single parameter $\tau$ given above the detector with a smaller $\tau$ has a higher output SINR.

The analytical BER performance is evaluated using the approximation

$$
\mathrm{P}_{\mathrm{e}} \cong \mathrm{Q}(\sqrt{\operatorname{SINR}})
$$

This effectively treats the output interference-plus-noise of the estimated detector as having a Gaussian distribution. The output of an exact linear MMSE detector is well-approximated with a Gaussian distribution.

\section{Results}

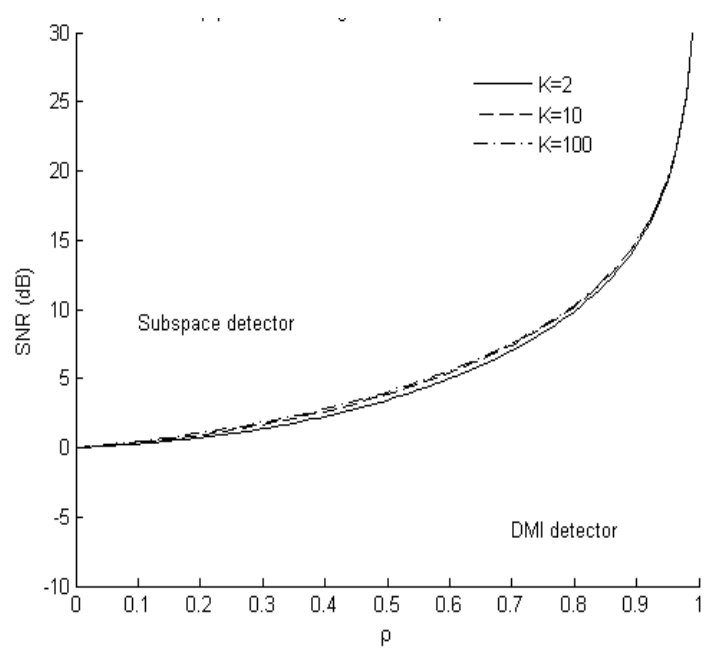

Figure 1. SNR Vs $\rho$ for two blind detectors in each $\mathrm{K}$ 


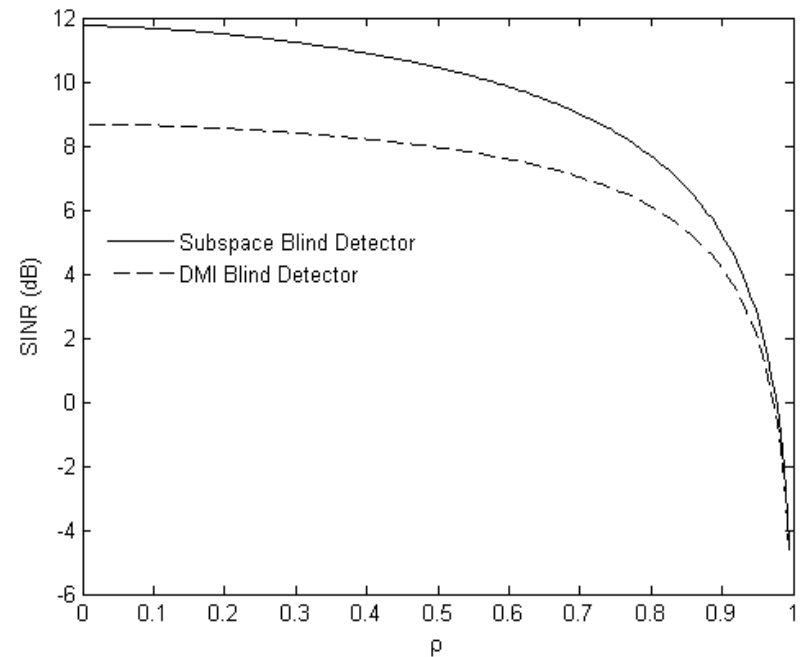

Figure 2. Average output SINR vs $\rho$ for two blind detectors. $\mathrm{N}=16, \mathrm{~K}=6$, $\mathrm{M}=150, \mathrm{SNR}=15 \mathrm{~dB}$

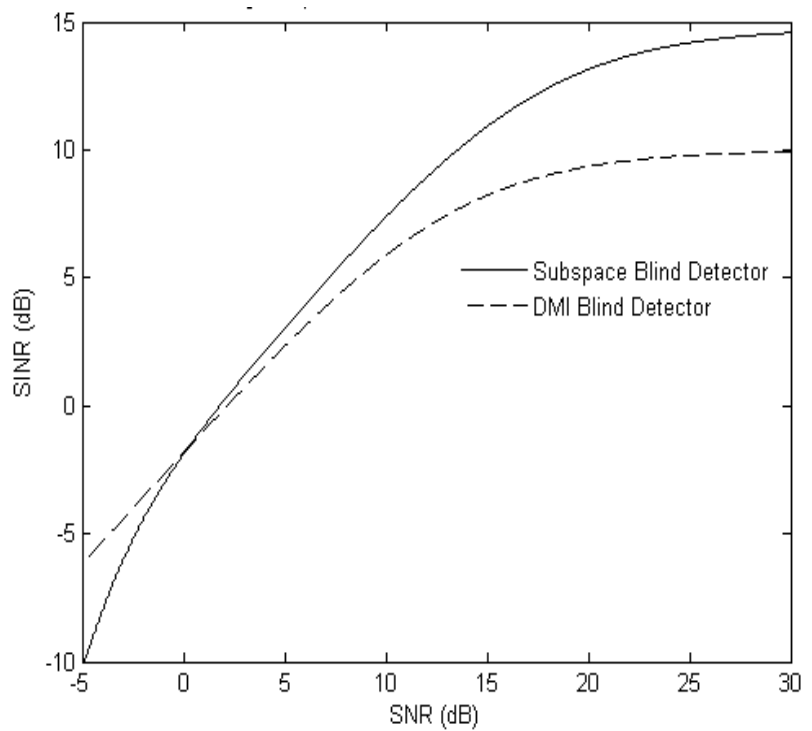

Figure 3. Average output SINR vs SNR for two blind detectors. $\mathrm{N}=16$, $\mathrm{K}=6, \mathrm{M}=150, \rho=0.4$

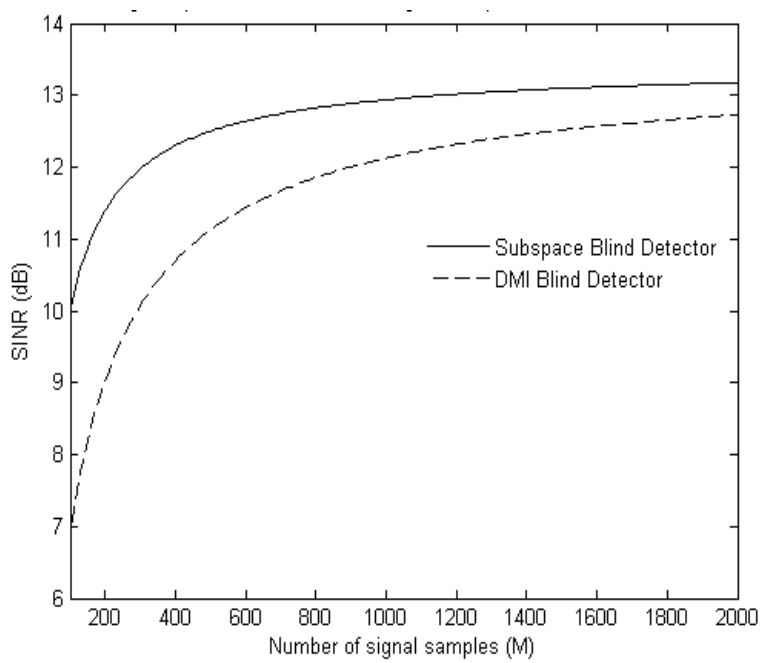

Figure 4. Average output SINR vs $\mathrm{M}$ for two blind detectors. $\mathrm{N}=16, \mathrm{~K}=6$, $\mathrm{SNR}=15 \mathrm{~dB}, \rho=0.4$

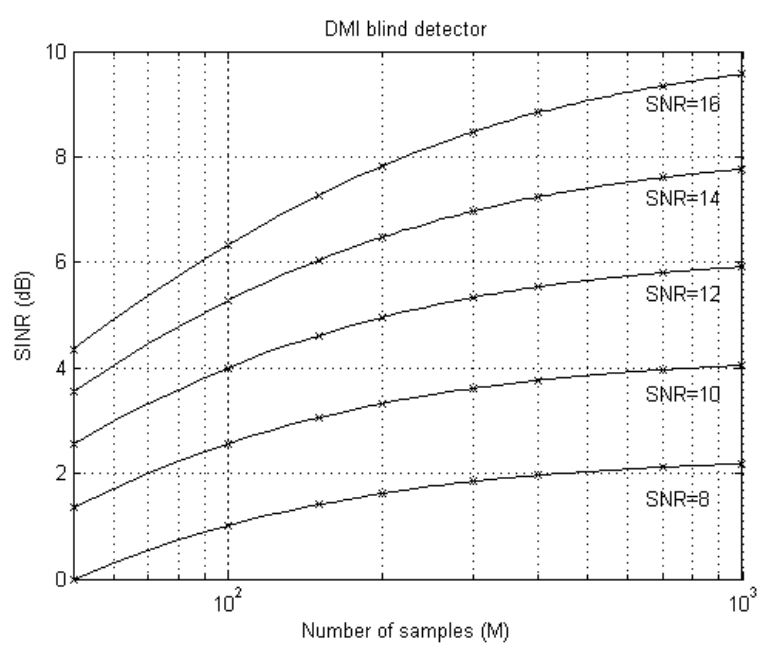

Figure 5a. Output average SINR vs Number of signal samples (M) for DMI detector. $\mathrm{N}=13, \mathrm{~K}=11$

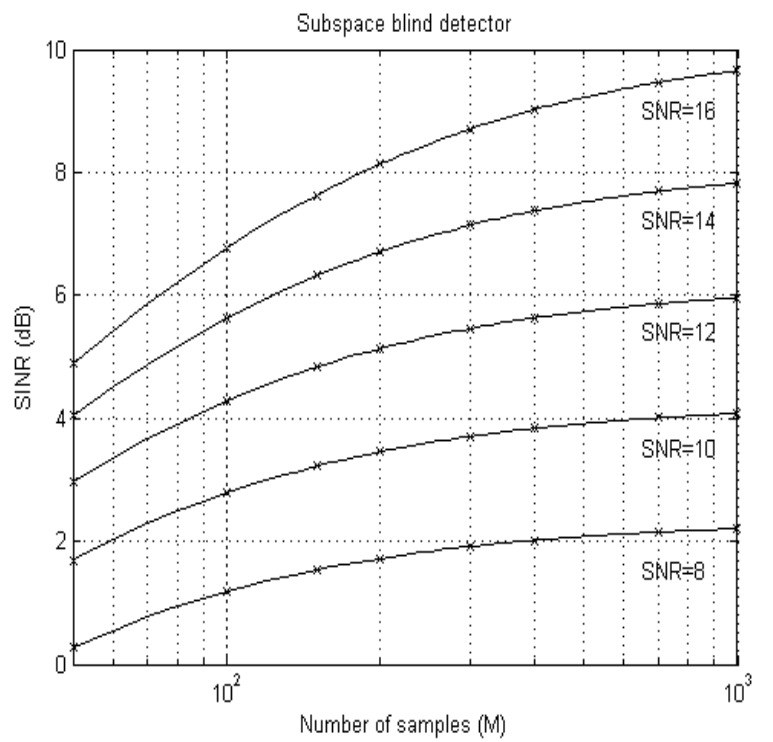

Figure 5 b. Output average SINR vs Number of signal samples (M) for subspace detector. $\mathrm{N}=13, \mathrm{~K}=11$

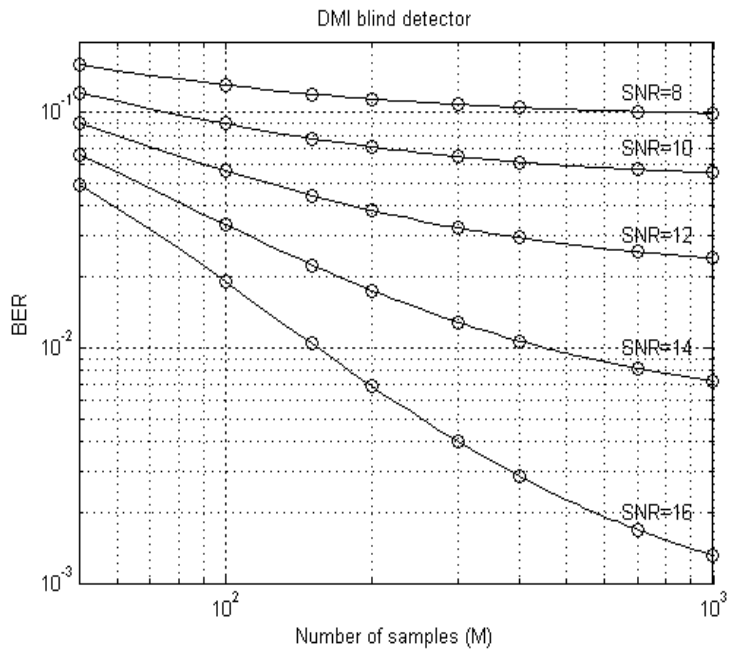

Figure 6a. BER vs Number of signal samples (M) for DMI detector. $\mathrm{N}=13$, $\mathrm{K}=11$ 


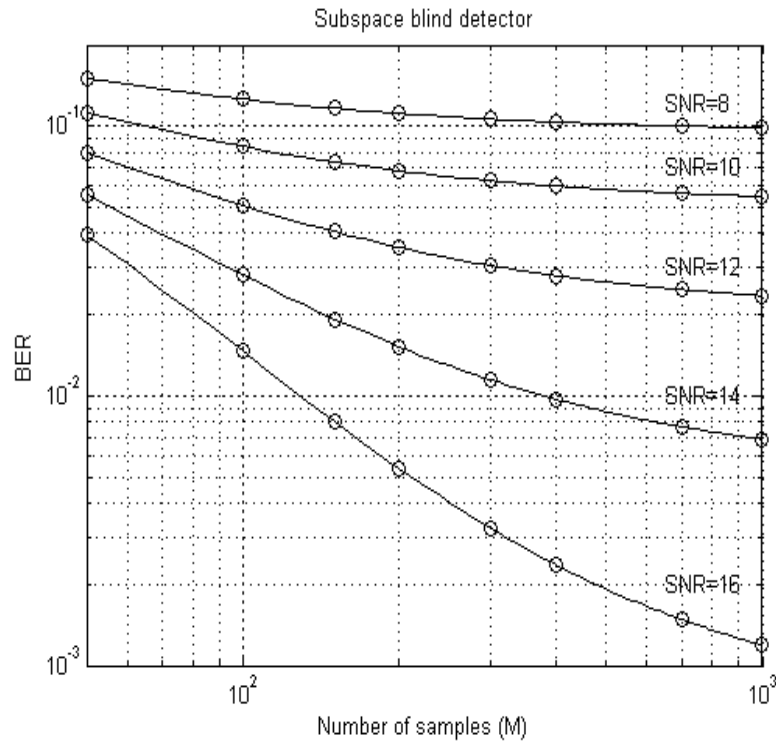

Figure 6b. BER vs Number of signal samples (M) for subspace detector. $\mathrm{N}=13, \mathrm{~K}=11$

\section{Conclusions}

In this paper, the performance of blind multiuser detectors is analyzed. The blind multiuser detectors considered are DMI detector and subspace detector. The analysis is performed by means of the Signal to Interference and Noise ratio (SINR) and Bit Error Rate (BER) obtained during our simulation. We have also compared the performance of MMSE blind detector with subspace blind.

Fig. 1 shows SNR Vs $\rho$ for different values of K. It is seen that the subspace blind detector outperforms the DMI blind detector.

This phenomenon is more clearly seen in Fig. 2 and 3. where the performance of the two blind detectors is compared as a function of $\rho$ Vs SINR and SINR Vs SNR respectively.

The performance of the two blind detectors as a function of the number of signal samples M and SINR is plotted in Fig. 4, where it is seen that, for large $\mathrm{M}$, both detectors converge to the true linear MMSE detector, with the subspace blind detector converging much faster than the DMI blind detector; and the performance gain offered by the subspace detector is quite significant for small values of $\mathrm{M}$.

In Fig.5a\&b depicts SINR Vs M for each detector, for estimating the detector at some fixed SNR.
The analytical BER performance is evaluated using the approximation given by (43) as shown in Fig .6a\&b which effectively treats the output interference-plus-noise of the estimated detector as having Gaussian distribution. The output of an exact linear MMSE detector is well-approximated with Gaussian distribution.

The BER performance of subspace approach is better than that of DMI approach and decreases with increasing SNR.

\section{REFERENCES}

[1] Dr. Allen C Chen, "Overview of CDMA for wireless comunications", 2008

[2] Xiadong Wang and H.Vincent Poor, Blind Multiuser Detection: A subspace Approach,'IEEE Transactions on information theory, Vol. 44 No.2, March 1998."

[3] Xiadong Wang and H.Vincent Poor, "Wireless communication systems: Advanced Techniques for signal reception", Pearson Education,2004

[4] Simon Haykin, "Digital Communications", John Wiley \&So ns, 2008

[5] U. Mitra and H.V. Poor. Analysis of an adaptive decorrelating detector for synchronous CDMA channels. IEEE Trans. Commun., COM-44(2):257-268, Feb. 1996

[6] A. Høst-Madsen and X. Wang. Performance of blind and group-blind multiuser detectors. In Proc. 38th Annual Allerton Conference on Communications, Computing and Control, Monticello, Illinois, Oct. 2000

[7] A. Host-Madsen and X. Wang. Performance of blind multiuser detectors. In Proc. 10th International Symposium on Information Theory and Its Applications (ISITA'00), Honolulu, HI, Nov. 2000

[8] M. Honig and H. V. Poor, "Adaptive interference suppression in wireless communication systems," in H. V. Poor and G. W. Wornell, Eds., Wireless Communications: Signal Processing Perspectives. Upper Saddle River, NJ: Prentice Hall, 1998

[9] U. Mitra and H. V. Poor, "Adaptive receiver algorithms for near-far resistant CDMA," IEEE Trans. Commun., vol. 43, pp. 1713-1724, 1995

[10] "Analysis of an adaptive decorrelating detector for synchronous CDMA channels," IEEE Trans. Commun., vol. 44, Feb. 1996

[11] J. G. Proakis, Digital Communications, 3rd ed. New York: McGraw- Hill, 1999 